\title{
A spin label study of the effect of chrysotile asbestos on erythrocyte membranes
}

\author{
E GENDEK, G BARTOSZ, AND W LEYKO
}

From the Department of Biophysics, Institute of Biochemistry and Biophysics, University of $七 6 d z$, 90-237 Łódz, and the Department of Aerosols, Institute of Occupational Medicine, 90-950 Łódź, Poland

ABSTRACT Alterations in erythrocyte membranes caused by UICC B chrysotile asbestos fibres were studied in red cell ghosts using the spin label technique. The electron paramagnetic resonance (EPR) spectra of two sulphydryl reactive spin labels and one fatty acid spin probe in erythrocyte ghosts showed membrane protein modifications but no changes in lipid fluidity caused by the haemolytic chrysotile asbestos fibres.

Asbestos is an agent associated with such occupational diseases as asbestosis, lung cancer, mesothelioma, and, less commonly cancers of oesophagus, stomach, colon, and rectum. ${ }^{1-3}$ Human diseases connected with the inhalation of dusts containing asbestos have been reproduced experimentally in animals. ${ }^{45}$ Although haemolysis of erythrocytes plays no part in the pathogenesis of these diseases, the haemolytic effect of asbestos is often used to quantify the biological activity of mineral dusts.

It is well documented that chrysotile fibres induce haemolysis in vitro ${ }^{6-9}$ but the mechanism of this haemolysis remains obscure. Macnab and Harington $^{6}$ and Allison ${ }^{10}$ claimed that membrane glycoproteins play a crucial part in that phenomenon. On the other hand, Jaurand et al proposed that the adsorption of membrane phospholipids to the asbestos fibres is responsible for the chrysotile haemolysis. ${ }^{89}$ In this study we used the spin label technique to determine the effects of chrysotile fibres on the lipid and protein components of the erythrocyte membrane.

\section{Material and methods}

All experiments were carried out with UICC B chrysotile. Erythrocyte ghosts were prepared from citrated bovine blood by the method of Dodge et al. ${ }^{11}$ The two sulphhydryl reactive spin labels: 4 - maleimido - 2,2,6,6 - tetramethylpiperidino - oxyl (MSL) and 4-(2-iodacetamido)-2,2,6,6-tetramethylpiperidino-oxyl (ISL), and a spin labelled fatty acid analogue, 5-doxyl stearic acid (5NS), were purchased from Syva.*

Small aliquots of ethanol solutions of the labels were added to freshly prepared ghost syspensions. The final spin label concentrations were $5 \cdot 10^{-4}$ $\mathrm{nmol} / \mathrm{l}$ and the final ethanol concentration did not exceed $1 \%(\mathrm{v} / \mathrm{v})$. The samples were incubated at $4^{\circ} \mathrm{C}$ for 12-14 hours (MSL, ISL) or one hour at room temperature (5NS) and unreacted spin label was removed by washing the ghosts with the buffer used in the final part of the preparation procedure (10 $\mathrm{mmol} / \mathrm{l}$ sodium phosphate, $\mathrm{pH} 7 \cdot 4$ ).

The protein concentration of the ghost suspensions was measured by the method of Lowry et al $^{12}$ and adjusted to $3 \mathrm{mg} / \mathrm{ml} .0 .5 \mathrm{ml}$ of ghost suspensions were mixed with various amounts of chrysotile fibres $(0-10 \mathrm{mg})$ that had been wetted previously with $0 \cdot 2$ $\mathrm{ml}$ of the buffer. The samples were incubated at $37^{\circ} \mathrm{C}$ for one hour and EPR spectra were recorded in a SE/X-28 spectrometer (Wroclaw Technical University) at ambient temperature $\left(22-23^{\circ} \mathrm{C}\right)$. The measurements were repeated after 24 hour incubation of the samples at $4^{\circ} \mathrm{C}$.

All the experiments were repeated at least five to seven times on different membrane preparations. The results are presented as mean values \pm SD. Calculations of statistical significance of differences were made using Student's $t$ test after checking the data with Dixon's $Q$ test. For clarity of comparison, the asbestos induced changes in EPR spectral parameters of spin labelled membranes are expressed as a percentage of the appropriate control values taken as $100 \%$.

\footnotetext{
*Palo Alto, California 94 304, USA.
} 


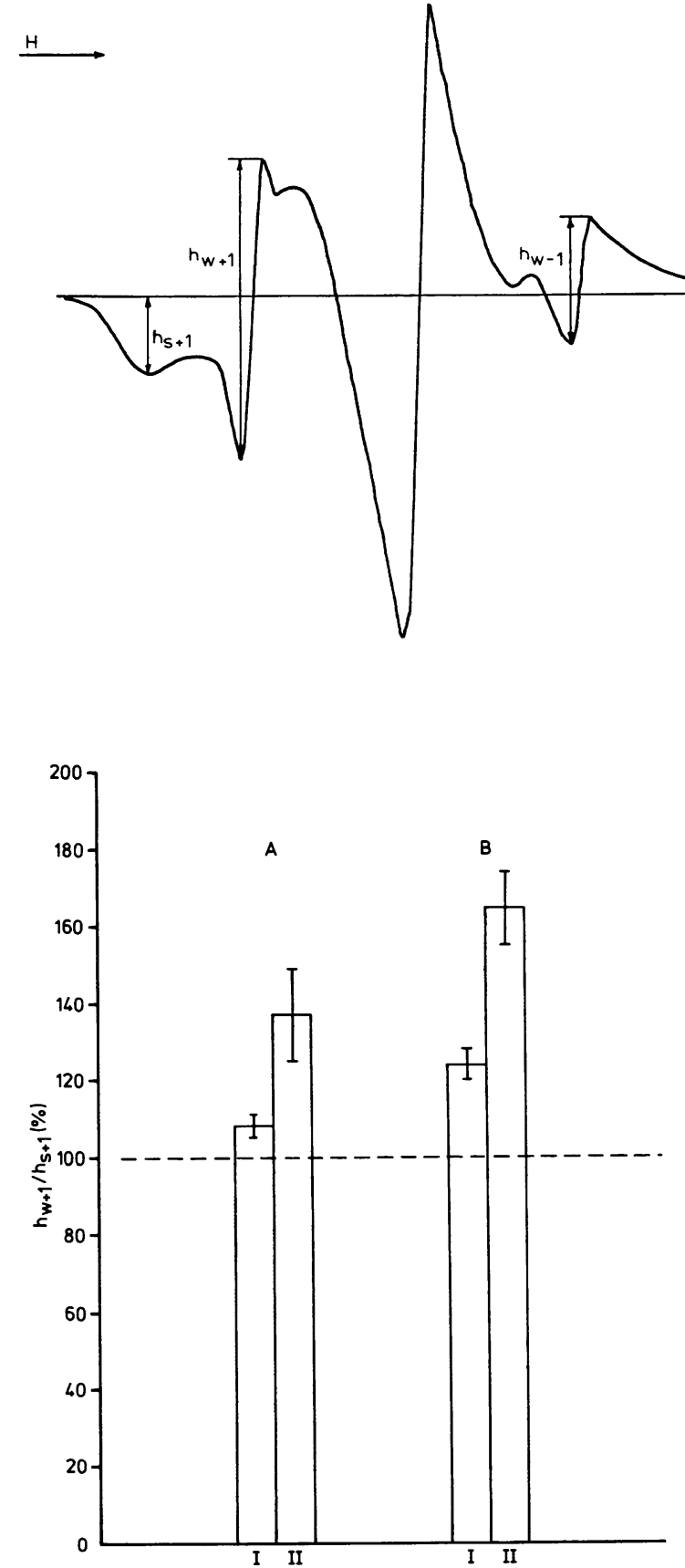

Fig 2 Effect of chrysotile $B$ on the $h_{w+} / h_{w+}$ ratio of MSL bound to erythrocyte membranes. Absolute control value: $3.44 \pm 0.16$ (=100\%); $A-1$ h incubation, $B-24 h$ incubation, I-7 mg of asbestos/ml of ghost suspension, II-20 $\mathrm{mg}$ of asbestos/ml of ghost suspension. For all differences with respect to control, $p<0.01$.
Fig 1 EPR spectrum of erythrocyte membranes labelled with $M S L ; h_{w+1}$ and $h_{s+1}$-heights of lowfield peaks of weakly immobilised and strongly immobilised, respectively, spin label residues. Measurement conditions: modulation amplitude $0.25 \mathrm{mT}$, scanning range $10 \mathrm{mT}$, time constant $0 \cdot 3 \mathrm{~s}$, scanning time $250 \mathrm{~s}$.

\section{Results}

Figure 1 shows a typical EPR spectrum of MSL bound to erythrocyte membranes. It consists of "broad line" and "sharp line" components. The first is due to a population of strongly immobilised (S) spin label residues and the second to weakly immobilised (W) residues of the spin label, apparently located more superficially. ${ }^{13}$ After chrysotile treatment of the erythrocyte ghosts, an increase was observed in the ratios of the spectral amplitudes of the weakly immobilised to the strongly immobilised spin label residues in the low field part of the EPR spectrum, $\mathrm{h}_{\mathrm{w}_{+}} / \mathrm{h}_{\mathrm{s}_{+}}$(fig 2 ).

Simple EPR spectra of membrane bound ISL residues permit evaluation of the rotational correlation time of the label residues, $\tau_{\mathrm{c}}::^{14}$

$\tau_{\mathrm{c}}=\mathrm{k} \Delta \mathrm{W}_{\mathrm{o}}\left(\left(\mathrm{h}_{\mathrm{o}} / \mathrm{h}_{-_{1}}\right)^{1 / 2}-1\right)$,

where: $k=$ constant $\left(\mathrm{k}=6.5 \times 10^{-10} \mathrm{~s} \mathrm{mT}^{-1}\right)$,

$\Delta \mathrm{W}_{\mathrm{o}}=$ width of the midfield peak of EPR spectrum,

$h_{o}$ and $h_{-1}=$ heights of the midfield and the highfield peaks of EPR spectrum, respectively (fig 3 ).

Chrysotile treatment resulted in an increase of $\tau_{c}$ values of ISL-labelled erythrocytes ghosts (fig 4).

EPR spectra of spin labelled fatty acids which incorporate into cellular membranes like their natural counterparts give information about the rigidity of the membrane lipid matrix. From such spectra, the order parameter of the membrane lipids, $\mathrm{S}$, is usually derived ${ }^{15}$ :

$\mathbf{S}=\frac{\mathbf{A}_{\|}-\mathbf{A}_{\perp}}{\mathbf{A}_{\|}^{\prime}-\mathbf{A}_{\perp}^{\prime}} \cdot \frac{\mathbf{a}_{\mathbf{n}}}{\mathbf{a}^{\prime}{ }^{\prime}}$,

where $A_{\mid l}$ and $A_{\perp}$ refer to outer and inner hyperfine 


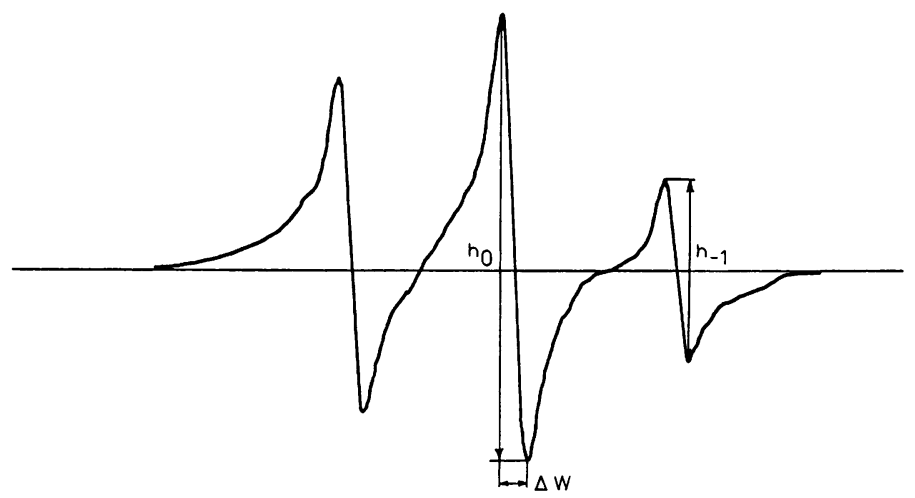

Fig 3 EPR spectrum of erythrocyte membranes labelled with ISL; $\Delta \mathrm{W}_{0}-$ midfield peak width, $h_{o}$ and $h_{-1}$ - heights of the midfield and highfield peaks, respectively.

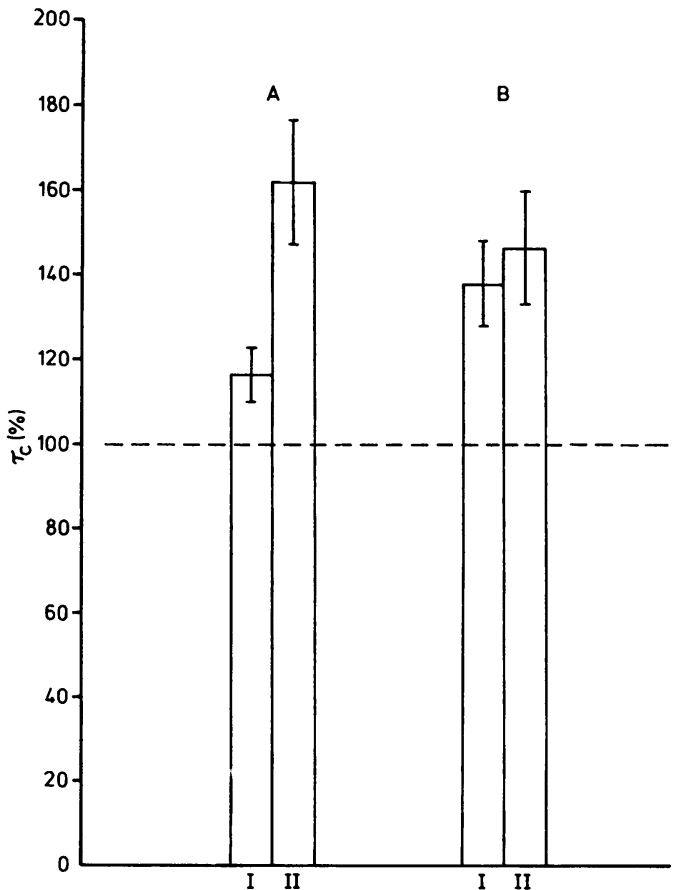

splitting read from the spectra (fig 5), $A^{\prime}{ }_{\mid 1}$ and $A^{\prime}{ }_{\perp}$ refer to completely ordered systems, $a_{n}=1 / 3\left(A_{\|}+\right.$ $\left.2 A_{\perp}\right), a_{n}^{\prime}=1 / 3\left(A_{1 \mid}^{\prime}+2 A^{\prime}{ }_{1}\right)$. For control membranes the value of $S$ was $0 \cdot 61 \pm 0 \cdot 01$. No alterations of this value was observed after chrysotile treatment.

\section{Discussion}

The spin label method, enabling an independent probing of the lipid and protein components of the membrane, was used in studies of the structural
Fig 4 Effect of chrysotile $B$ on rotational correlation time of membrane bound ISL. Absolute control value: $(8.64 \pm$ $0.76) \times 10^{-10} s(=100 \%)$. Designations as in fig 2 . For the two differences with respect to the control value, $p<0 \cdot 01$.

changes induced in the erythrocyte membrane by chrysotile treatment. It was hoped by this means to shed light on the question of which components of the membrane are responsible for the chrysotile induced haemolysis.

Spectra of membrane bound MSL showed an increase in the ratio of signal heights corresponding to weakly immobilised and strongly immobilised spin label residues. Spectra of ISL labelled membranes indicate an increase in the rotational correlation time of the residues of the label. These changes in the state of membrane proteins detected with two 


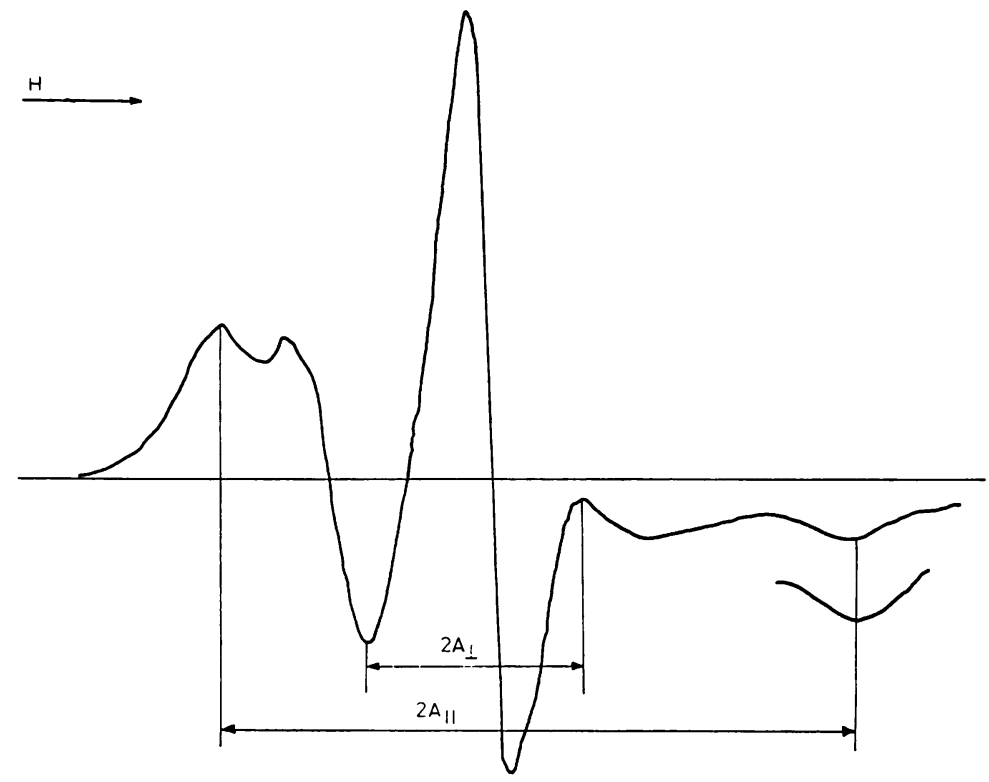

Fig 5 EPR spectrum of erythrocyte membranes labelled with $5 N S ; A_{11}$ and $A_{\perp}$ - outer and inner hyperfine splitting, respectively.

different labels were augmented with increasing dose of asbestos and prolongation of incubation time. On the other hand, no detectable alterations in lipid rigidity were induced by chrysotile fibres even though the doxyl group of 5NS is located relatively close to the membrane surface.

These results do not support the suggestion of Jaurand $e t a l^{8}$ that "the effect of chrysotile asbestos on red cells is at least partly, if not completely, attributable to lipid extraction and adsorption on the fibres." On the contrary, they indicate that this effect is due primarily to interaction of asbestos with membrane proteins.

The observed alterations in EPR spectra of protein bound spin labels can be due to at least two factors: conformational changes of the membrane proteins, or a direct interaction of protein bound spin label residues with the chrysotile. The first possibility seems more probable since the data obtained indicate an immobilisation of ISL residues and a decrease in the relative amount of strongly immobilised MSL residues. If direct interaction of membrane bound spin labels with the asbestos was responsible for the changes observed, an immobilisation of both labels would be expected. On the other hand, such a pattern of changes is typical for the conformational changes of erythrocyte membrane proteins induced by other factors. ${ }^{15}$ So far as current hypotheses on the mechanism of haemolytic action of asbestos are concerned, the results of this study are compatible with that ${ }^{1016}$ which states that chrysotile induces the movement of glycoproteins in the plane of the erythrocyte membrane to form clusters from which lipid hydrocarbon chains are excluded. Such a clustering would be associated with conformational changes in the membrane proteins which might lead to an impairment of the permeability of the membrane resulting in haemolysis.

\section{References}

' Selikoff IJ, Hammond EC, Seidman H. Mortality experience of insulation workers in the United States and Canada, 19431976. Ann NY Acad Sci 1979;330:91-116.

${ }^{2}$ Selikoff IJ. Occupational respiratory diseases. In: Last JM, ed. Public health and preventive medicine. 11th ed. Eaglewood Cliffs, NJ: Appleton-Century-Crofts, 1980.

${ }^{3}$ Seidman H, Selikoff IJ, Hammond EC. Short-term asbestos work exposure and long-term observation. Ann NY Acad Sci 1979;330:61-90.

4 Wagner JC, Berry G, Skidmore JW, Timbrell V. The effects of the inhalation of asbestos in rats. Br J Cancer 1974;29:252-69.

5 Smith WE, Hubert DD. The intrapleural route as a means for estimating carcinogenicity. In: Karbe E, Park JF, eds. Experimental lung cancer. New York: Springer-Verlag, 1974;93101.

- Macnab G, Harington JS. Haemolytic activity of asbestos and other mineral dusts. Nature 1967;214:522-3.

${ }^{7}$ Harington JS, Miller K, Macnab G. Haemolysis by asbestos. Environ Res 1971;4:95-117.

8 Jaurand MC, Magne L, Bignon J. Inhibition by phospholipids of haemolytic action of asbestos. Br J Ind Med 1979;36:113-6.

- Jaurand MC, Thomassin JH, Baillif P, Magne L, Touray JC, Bignon J. Chemical and photoelectron spectrometry analysis of the adsorption of phospholipid model membranes and red blood cell membranes on to chrysotile fibres. $\mathrm{Br} J$ Ind $\mathrm{Med}$ 1980;37:169-74.

${ }^{10}$ Allison AC. The regulation of proliferation in animal cells. Cold Spring: Harbour Press, 1974. 
" Dodge JT, Mitchell C, Hanahan DJ. The preparation and chemical characteristics of hemoglobin free ghosts of human erythrocytes. Arch Biochem Biophys 1963;100:119-30.

${ }^{12}$ Lowry OH, Rosebrough NJ, Farr AL, Randall RJ. Protein measurement with the Folin phenol reagent. J Biol Chem 1951;193:265-75.

${ }^{13}$ Holmes DE, Piette LH. Effects of phenothiazine derivatives on biological membranes: drug-induced changes in electron spin resonance spectra from spin-labelled erythrocyte ghost membranes. J Pharmacol Exp Ther 1970;173:78-84.
${ }^{14}$ Keith AD, Butterfield C, Snipes W. Spin labelled neurospora mitochondria. Biophys J 1970;10:618-29.

is Grzelińska E, Bartosz G, Gwoździński K, Leyko W. A spin label study of the effect of gamma radiation on erythrocyte membrane. Influence of lipid peroxidation on membrane structure. Int J Radiat Biol 1979;36:325-34.

${ }^{16}$ Harington JS. The biological effects of mineral fibres, especially asbestos, as seen from in vitro and in vivo studies. In: $\mathbf{L a}$ pathologie de l'asbeste. Paris: Masson, 1976. 